\title{
Germinação e vigor de sementes de gabiroba em função do tamanho do fruto e semente ${ }^{1}$
}

\author{
Daiane Mugnol Dresch², Silvana de Paula Quintão Scalon², \\ Tathiana Elisa Masetto ${ }^{2}$, Maria do Carmo Vieira²
}

\begin{abstract}
Germination and vigor of Campomanesia adamantium seeds according to fruit and seed size

The knowledge on biometric aspects of fruits and seeds and their influence on germination are important for the production and properties of native species. This study aimed at evaluating the influence of fruit and seed size on the germination and vigor of Campomanesia adamantium seeds. For the biometric characterization, 120 fruits were randomly selected and visually divided into four classes, with predominance for size, in which longitudinal and transversal diameters and mass of seeds were measured. The seed characterization was carried out in 30 fruits of each class, by determining the number of whole, empty and total seeds of every fruit. The seeds physiological potential, according to fruit size, was evaluated with the aid of the following tests: imbibition curve, moisture content, germination percentage and speed index, seedling length, total fresh and dry matter of seedlings. A completely randomized design, with four treatments, was used. Fruits were respectively classified according to their longitudinal and transversal diameters as small $(12.71 \mathrm{~mm} ; 12.46 \mathrm{~mm})$, medium small $(15.38 \mathrm{~mm} ; 15.01 \mathrm{~mm})$, medium large $(18.84 \mathrm{~mm}$; $18.02 \mathrm{~mm}$ ) and large $(22.74 \mathrm{~mm} ; 22.36 \mathrm{~mm})$. The classes of small, medium small and medium large fruits presented seeds with higher germination percentage and speed index, while seedlings with higher biomass accumulation were observed for large fruits.
\end{abstract}

KEY-WORDS: Campomanesia adamantium (Cambess.) O. Berg (Myrtaceae); fruits biometric aspects; seeds dimensions.

\section{INTRODUÇÃO}

A espécie Campomanesia adamantium (Cambess.) O. Berg (Myrtaceae), conhecida como gabiroba, é uma frutífera nativa e não cultivada, porém abundante na região de campos e Cerrado de Goiás, Minas Gerais e do Mato Grosso do Sul até Santa Catarina (Lorenzi et al. 2006). Os frutos coletados em diferentes estádios de amadurecimento apresentam potencial para serem utilizados in natura, na indús-

\section{RESUMO}

O conhecimento dos aspectos biométricos de frutos e sementes e a sua influência na germinação são importantes para a produção e características de espécies nativas. Este trabalho objetivou avaliar a influência do tamanho do fruto e da semente na germinação e vigor de sementes de gabiroba (Campomanesia adamantium). Para a caracterização biométrica, foram selecionados, aleatoriamente, 120 frutos, divididos, visualmente, em quatro classes, com predominância de tamanho, nas quais foram avaliados o diâmetro longitudinal e transversal e a massa das sementes. A caracterização da semente foi realizada em 30 frutos de cada classe, por meio da determinação do número de sementes íntegras, vazias e total de cada fruto. O potencial fisiológico das sementes, em função do tamanho dos frutos, foi analisado por meio dos seguintes testes: curva de embebição, grau de umidade, percentagem e índice de velocidade de germinação, comprimento de plântulas, massa fresca e massa seca total de plântulas. $\mathrm{O}$ delineamento foi inteiramente casualizado, com quatro tratamentos. Os frutos foram classificados de acordo com o diâmetro longitudinal e transversal, respectivamente, como pequeno $(12,71 \mathrm{~mm} ; 12,46 \mathrm{~mm})$, médio pequeno $(15,38 \mathrm{~mm} ; 15,01 \mathrm{~mm})$, médio grande $(18,84 \mathrm{~mm}$; $18,02 \mathrm{~mm})$ e grande $(22,74 \mathrm{~mm} ; 22,36 \mathrm{~mm})$. As classes de frutos pequeno, médio pequeno e médio grande apresentaram sementes com maior percentagem e velocidade de germinação, enquanto frutos classificados como grandes proporcionaram plântulas com maior acúmulo de biomassa.

PALAVRAS-CHAVES: Campomanesia adamantium (Cambess.) O. Berg (Myrtaceae); caracterização biométrica de frutos; dimensões de sementes.

tria de alimentos, e como flavorizantes, na indústria de bebidas, devido à elevada acidez, ácido ascórbico (vitamina C), minerais, fibras alimentares e hidrocarbonetos monoterpênicos, presentes em maior quantidade no óleo volátil dos frutos e que lhes conferem o aroma cítrico (Valillo et al. 2006). No ambiente nativo, são encontrados frutos com expressiva variedade de formas e tamanhos (Paoli \& Bianconi 2008).

Nesse sentido, as características morfológicas de sementes e frutos constituem critério bastante

1. Trabalho recebido em jan./2013 e aceito para publicação em ago./2013 ( $\mathrm{n}^{\circ}$ registro: PAT 22087).

2. Universidade Federal da Grande Dourados (UFGD), Faculdade de Ciências Agrárias, Dourados, MS, Brasil.

E-mails: daiamugnol@hotmail.com, silvanascalon@ufgd.edu.br, tmasetto@gmail.com, vieiracm@terra.com.br. 
seguro para a identificação das plantas, segundo a espécie, e auxiliam na interpretação dos testes de germinação em laboratório e orientam quanto ao armazenamento de sementes e métodos de cultivo, além de facilitarem o reconhecimento das espécies em bancos de sementes no solo (Donadio \& Demattê 2000, Ramos \& Ferraz 2008).

Os métodos adequados para análise de sementes de espécies florestais têm sido alvo de grande interesse, especialmente quando visam à obtenção de informações que expressam a qualidade fisiológica da semente (Cruz \& Carvalho 2003).

A separação das sementes por classes de tamanho, para determinação da qualidade fisiológica, por meio de testes de germinação e vigor, tem sido bastante empregada, visando a encontrar a classe ideal para multiplicação das diversas espécies vegetais (Torres 1994). Neste contexto, a classificação das sementes por tamanho ou peso é uma estratégia que pode ser adotada para uniformizar a emergência de plântulas e a obtenção de mudas de tamanhos semelhantes e/ ou maior vigor (Carvalho \& Nakagawa 2000).

Para muitas espécies, o peso da semente é indicativo da sua qualidade fisiológica, sendo que, em um mesmo lote, sementes leves, normalmente, apresentam menor desempenho do que as pesadas (Bezerra et al. 2004).

A maior quantidade de reserva aumenta a possibilidade de sucesso no estabelecimento da plântula, uma vez que possibilita a sua sobrevivência por tempo maior, em condições ambientais que ainda não permitam o aproveitamento das reservas nutricionais e hídricas do solo e a realização da fotossíntese (Haig \& Westoby 1991).

Vários autores relataram o efeito do tamanho de sementes na germinação e no estabelecimento de plântulas. Costa et al. (2006) observaram que as sementes de jambo-vermelho (Syzygium malaccense) de menor tamanho possuem menor desempenho germinativo e vigor do que as de tamanho médio e maior. Klein et al. (2007) relataram que sementes de pitanga (Eugenia uniflora L.) de tamanho médio e grande apresentam maiores médias para os parâmetros avaliados. Entretanto, Pereira et al. (2011) observaram que sementes médias de jatobá-do-cerrado (Hymenaea stigonocarpa var. stigonocarpa) apresentam maior capacidade de emissão da raiz primária que sementes grandes.

A germinação de sementes consiste na reativação do crescimento do embrião, por meio de uma sequência ordenada de eventos metabólicos, resultando na ruptura do tegumento, pela raiz primária (Bewley \& Black 1994). O início deste processo se dá pela absorção de água pelas sementes e termina com o alongamento do eixo embrionário.

A velocidade de absorção das sementes varia de acordo com a espécie, disponibilidade hídrica, temperatura, área de contato, composição química dos tecidos de reserva e condições fisiológicas das sementes (Bewley \& Black 1994, Carvalho \& Nakagawa 2000).

De acordo com Bortolotto et al. (2008), pesquisas têm sido realizadas com o objetivo de associar a velocidade de hidratação da semente com o seu potencial fisiológico, à medida em que a velocidade de absorção pode ser afetada pela qualidade das sementes, constituindo-se, assim, em indicativo de qualidade. Entretanto, para as sementes de espécies florestais nativas, estudos, neste sentido, ainda são escassos.

Conhecimentos sobre os aspectos biométricos de frutos e sementes, e sua influência na germinação, podem auxiliar na tomada de decisão, durante a coleta dos frutos e, consequentemente, na produção e estabelecimentos de mudas de espécies tropicais nativas. Assim, objetivou-se, com este trabalho, avaliar o efeito do tamanho dos frutos e sementes na germinação e vigor de sementes de gabiroba (C. adamantium).

\section{MATERIAL E MÉTODOS}

Os frutos de gabiroba foram coletados no final do mês de dezembro de 2011, a partir de 30 matrizes próximas entre si, localizadas em região de Cerrado (stricto sensu), na cidade de Ponta Porã (MS). Após a coleta, os frutos foram levados ao Laboratório de Nutrição e Metabolismo de Plantas da Universidade Federal da Grande Dourados (UFGD), em Dourados (MS), onde foram lavados em água corrente, descartando-se os frutos danificados. Posteriormente, foram mensurados as variáveis biométricas de frutos e sementes e a germinação e o vigor das sementes.

Para a caracterização biométrica, foram selecionados, aleatoriamente, 120 frutos, divididos, visualmente, em quatro classes, com predominância de tamanho, nas quais foram tomadas as medidas de diâmetro ( $\mathrm{mm}$ ) longitudinal e transversal, utilizando-se paquímetro digital com precisão de $0,01 \mathrm{~mm}$. A massa (g) das sementes também foi determinada, 
com o auxílio de uma balança digital com precisão de $0,0001 \mathrm{~g}$.

Para a caracterização das sementes, foram selecionados, aleatoriamente, 30 frutos de cada classe, os quais foram cortados transversalmente, para a extração das sementes. Determinou-se o número de sementes íntegras (inteiras e com embrião), vazias (ausência de embrião) e total, para cada fruto. Posteriormente, as sementes íntegras foram lavadas e secas superficialmente, sobre uma toalha de papel, por 15 minutos, em temperatura ambiente $\left(25 \pm 1^{\circ} \mathrm{C} \mathrm{e}\right.$ $60 \%$ UR). Em seguida, foram determinadas as medidas de comprimento ( $\mathrm{mm}$ ), largura ( $\mathrm{mm}$ ) e espessura (mm), com o auxílio de paquímetro digital, enquanto a massa $(\mathrm{g})$ das sementes foi determinada em balança digital (precisão de $0,0001 \mathrm{~g}$ ).

Os dados de biometria de frutos e sementes foram analisados por meio das medidas de posição (médias, valores mínimo e máximo) e medidas de dispersão (desvio padrão e coeficientes de variação).

Para a caracterização da germinação e vigor das sementes, inicialmente, avaliou-se a absorção de água pelas sementes, em função das classes de tamanho dos frutos, sendo utilizadas quatro repetições de 10 sementes.

Primeiramente, as sementes foram pesadas e posicionadas sobre duas folhas de papel Germitest ${ }^{\mathbb{R}}$, umedecidas com água destilada, em quantidade equivalente a 2,5 vezes a massa do papel seco. As pesagens foram realizadas em balança com precisão de $0,0001 \mathrm{~g}$, a cada hora, durante as primeiras 8 horas de embebição, e, posteriormente, a cada 12 horas, até o final do sexto dia de embebição.

Para a determinação do potencial fisiológico das sementes, em função das classes de frutos, estes foram despolpados manualmente e as sementes lavadas em água corrente e secas sobre uma toalha de papel, em ambiente de laboratório $\left(25 \pm 1^{\circ} \mathrm{C}\right.$ e $60 \%$ UR), por 30 minutos. Após o processamento dos frutos para a extração das sementes, foram determinadas as seguintes características:

Grau de umidade: determinado pelo método da estufa (Brasil 2009) a $105 \pm 3^{\circ} \mathrm{C}$, por 24 horas, com três repetições de $5,0 \mathrm{~g}$ de sementes cada, sendo os resultados expressos em base úmida;

Germinação: realizada em rolos de papel Germitest $^{\circledR}$, com quatro repetições de 25 sementes cada, mantidas em germinadores do tipo B.O.D., à temperatura de $25^{\circ} \mathrm{C}$, sob luz branca constante. As avaliações finais foram realizadas aos 42 dias após a semeadura (Dresch et al. 2012), computando-se as percentagens de plântulas normais e utilizando-se, como critério, a emissão de parte aérea e sistema radicular desenvolvido;

Índice de velocidade de germinação (IVG): calculado pelo somatório do número de sementes germinadas a cada dia, dividido pelo número de dias decorridos entre a semeadura e a germinação, de acordo com a fórmula de Maguire (1962): $I V G=\left(G_{1} / N_{1}\right)+\left(G_{2} / N_{2}\right)+\left(G_{3} / N_{3}\right)+\ldots+\left(G_{n} / N_{n}\right)$, em que: $I V G=$ índice de velocidade de germinação; $G_{1}, G_{2}, G_{3}, \ldots, G_{n}=$ número de plântulas computadas na primeira, segunda, terceira e última contagem; $N_{1}, N_{2}, N_{3}, \ldots, N_{n}=$ número de dias da semeadura à primeira, segunda, terceira e última contagem;

Comprimento de plântulas: o comprimento de raízes, parte aérea e total das plântulas foi mensurado a partir de 10 plântulas provenientes do teste de germinação. Os resultados foram expressos em cm plântula ${ }^{-1}$;

Massa fresca e seca total: a massa fresca foi obtida a partir das pesagens de plântulas frescas em balança analítica de precisão $(0,0001 \mathrm{~g})$ e os resultados expressos em g plântula ${ }^{-1}$. A massa seca foi obtida a partir das plântulas secas de cada tratamento e repetição, em estufa regulada a $60^{\circ} \mathrm{C}$, por 48 horas, até obter-se a massa seca constante, medida em balança analítica de precisão $(0,0001 \mathrm{~g})$, com os resultados expressos em g plântula ${ }^{-1}$.

O delineamento foi inteiramente casualizado, com quatro tratamentos, e, para a análise de variância, as médias foram comparadas por meio do teste Tukey, a 5\%, utilizando-se o software Sisvar (Ferreira 2008). Os dados também foram submetidos ao teste de correlação linear simples (r).

\section{RESULTADOS E DISCUSSÃO}

Os frutos de gabiroba apresentaram elevada heterogeneidade, quanto ao tamanho, no momento da dispersão, o que permitiu classificá-los em quatro classes distintas: grande $(\mathrm{G})$, médio grande $(\mathrm{MG})$, médio pequeno (MP) e pequeno $(\mathrm{P})$ (Figura 1 e Tabela 1).

A diferença encontrada no tamanho dos frutos pode estar relacionada com a variabilidade genética das matrizes, associada a fatores ambientais, com destaque para a disponibilidade hídrica. Segundo Nogueira et al. (2010), as diferenças no tamanho dos 
frutos podem ser promovidas pela diversidade genética inerente a cada espécie, na população, sendo que a modificação no tamanho de frutos está relacionada não apenas ao patrimônio genético, mas, também, às condições determinadas pelo meio ambiente.

Os valores médios de diâmetro longitudinal e transversal foram, respectivamente, de $12,71 \mathrm{~mm}$ e $12,46 \mathrm{~mm}$, para os frutos classificados como P; $15,38 \mathrm{~mm}$ e $15,01 \mathrm{~mm}$, para MP; $18,84 \mathrm{~mm}$ e $18,02 \mathrm{~mm}$, para MG; e 22,74 $\mathrm{mm}$ e 22,36 $\mathrm{mm}$, para G (Tabela 1). Estes resultados assemelham-se aos mencionados na literatura, sendo que Melchior et al. (2006) relataram comprimento longitudinal de 14,0-22,0 mm e Oliveira et al. (2011) verificaram $15,0 \mathrm{~mm}$ e $20,99 \mathrm{~mm}$, para os comprimentos longitudinal e transversal de frutos de C. adamantium. Verificou-se, também, que os frutos com os maiores diâmetros longitudinal e transversal apresentaram os maiores valores de massa de sementes (Tabela 2).

Para a massa dos frutos, observaram-se diferenças entre os valores médios dos frutos P (1,2839 g), MP (2,0913 g), MG (3,7695 g) e $\mathrm{G}(7,2717 \mathrm{~g})$ (Tabela 1$)$. O resultado máximo encontrado para a massa de sementes provenientes de frutos grandes $(9,75 \mathrm{~g})$ assemelha-se ao relatado por Oliveira et al. (2011), que observaram valores máximos no intervalo de frequência de 9,00-9,99 g de frutos frescos de C. adamantium.

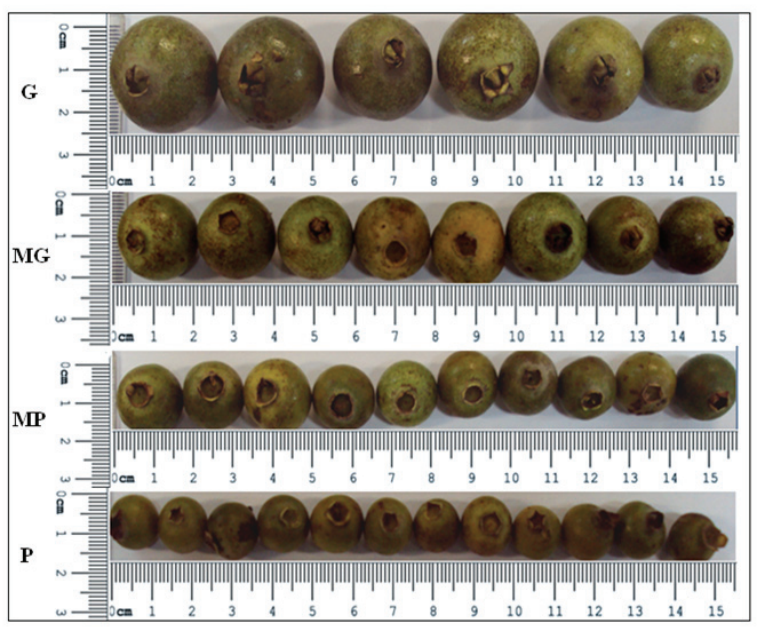

Figura 1. Frutos de gabiroba (Campomanesia adamantium) classificados pelo tamanho em: grande $(\mathrm{G})$, médio grande (MG), médio pequeno (MP) e pequeno $(\mathrm{P})$ (Dourados, MS, 2011).

Na Tabela 2, são apresentados os diâmetros e massas de sementes de C. adamantium, em função das classes dos frutos. Para os comprimentos das sementes, observou-se que os valores médios para os frutos $\mathrm{P}, \mathrm{MP}, \mathrm{MG}$ e $\mathrm{G}$ foram de 4,76 mm, 5,19 mm, $6,12 \mathrm{~mm}$ e $6,64 \mathrm{~mm}$, respectivamente. Com relação à largura, os frutos $\mathrm{P}, \mathrm{MP}, \mathrm{MG}$ e $\mathrm{G}$ apresentaram valores médios de 3,78 mm, 4,01 mm, 4,53 $\mathrm{mm}$ e 4,81 mm, respectivamente. Para a espessura das sementes,

Tabela 1. Diâmetro e massa dos frutos de gabiroba (Campomanesia adamantium), em função de classes de tamanho (Dourados, MS, 2011).

\begin{tabular}{|c|c|c|c|c|c|}
\hline \multirow{2}{*}{ Característica do fruto } & \multicolumn{3}{|c|}{ Valor } & \multirow{2}{*}{$\mathrm{DP}^{(1)}$} & \multirow{2}{*}{$\mathrm{CV}(\%)^{(2)}$} \\
\hline & Mínimo & Médio & Máximo & & \\
\hline \multicolumn{6}{|c|}{ Fruto pequeno $(P)$} \\
\hline Diâmetro longitudinal (mm) & 11,60 & 12,71 & 13,39 & 0,6347 & 4,99 \\
\hline Diâmetro transversal (mm) & 10,57 & 12,46 & 14,89 & 0,9548 & 7,66 \\
\hline Massa $(\mathrm{g})$ & 1,0191 & 1,2839 & 1,9342 & 0,2129 & 16,58 \\
\hline \multicolumn{6}{|c|}{ Fruto médio pequeno (MP) } \\
\hline Diâmetro longitudinal (mm) & 14,05 & 15,38 & 17,53 & 0,7826 & 5,09 \\
\hline Diâmetro transversal (mm) & 13,82 & 15,01 & 16,61 & 0,7053 & 4,70 \\
\hline Massa (g) & 1,5826 & 2,0913 & 2,8302 & 0,2762 & 13,21 \\
\hline \multicolumn{6}{|c|}{ Fruto médio grande (MG) } \\
\hline Diâmetro longitudinal (mm) & 16,73 & 18,84 & 20,93 & 1,2134 & 6,44 \\
\hline Diâmetro transversal (mm) & 16,21 & 18,02 & 20,35 & 1,0080 & 5,60 \\
\hline $\operatorname{Massa}(\mathrm{g})$ & 3,0952 & 3,7695 & 5,0492 & 0,5799 & 15,38 \\
\hline \multicolumn{6}{|c|}{ Fruto grande $(G)$} \\
\hline Diâmetro longitudinal (mm) & 20,42 & 22,74 & 25,71 & 1,7047 & 7,50 \\
\hline Diâmetro transversal (mm) & 19,15 & 21,36 & 26,31 & 2,3036 & 10,78 \\
\hline $\operatorname{Massa}(\mathrm{g})$ & 6,0364 & 7,2717 & 9,75 & 1,1711 & 16,11 \\
\hline
\end{tabular}

(1) DP: desvio padrão. ${ }^{(2)} \mathrm{CV}$ : coeficiente de variação. 
Tabela 2. Dimensão e massa de sementes de gabiroba (Campomanesia adamantium) provenientes de frutos com diferentes tamanhos (Dourados, MS, 2011).

\begin{tabular}{|c|c|c|c|c|c|}
\hline \multirow{2}{*}{ Característica da semente } & \multicolumn{3}{|c|}{ Valor } & \multirow{2}{*}{$\mathrm{DP}^{(1)}$} & \multirow{2}{*}{$\mathrm{CV}(\%)^{(2)}$} \\
\hline & Mínimo & Médio & Máximo & & \\
\hline \multicolumn{6}{|c|}{ Fruto pequeno $(P)$} \\
\hline Comprimento (mm) & 4,10 & 4,76 & 6,08 & 0,422 & 8,85 \\
\hline Largura (mm) & 3,14 & 3,78 & 4,93 & 0,429 & 11,32 \\
\hline Espessura (mm) & 1,59 & 2,03 & 2,78 & 0,292 & 14,39 \\
\hline Massa $(\mathrm{g})$ & 0,0162 & 0,0256 & 0,041 & 0,006 & 23,73 \\
\hline \multicolumn{6}{|c|}{ Fruto médio pequeno (MP) } \\
\hline Comprimento (mm) & 4,61 & 5,19 & 6,05 & 0,399 & 7,68 \\
\hline Largura (mm) & 3,20 & 4,01 & 5,88 & 0,579 & 14,46 \\
\hline Espessura (mm) & 1,62 & 2,15 & 2,60 & 0,304 & 14,16 \\
\hline Massa (g) & 0,0214 & 0,0325 & 0,0441 & 0,007 & 21,01 \\
\hline \multicolumn{6}{|c|}{ Fruto médio grande (MG) } \\
\hline Comprimento (mm) & 5,52 & 6,12 & 6,83 & 0,400 & 6,53 \\
\hline Largura $(\mathrm{mm})$ & 3,90 & 4,53 & 5,48 & 0,450 & 9,94 \\
\hline Espessura (mm) & 1,73 & 2,24 & 2,86 & 0,316 & 14,09 \\
\hline Massa (g) & 0,0277 & 0,0467 & 0,0667 & 0,010 & 14,46 \\
\hline \multicolumn{6}{|c|}{ Fruto grande $(G)$} \\
\hline Comprimento (mm) & 5,87 & 6,64 & 7,74 & 0,551 & 8,30 \\
\hline Largura (mm) & 4,11 & 4,81 & 5,54 & 0,386 & 8,02 \\
\hline Espessura (mm) & 1,77 & 2,17 & 2,43 & 0,161 & 7,42 \\
\hline Massa $(\mathrm{g})$ & 0,034 & 0,0504 & 0,0642 & 0,007 & 13,07 \\
\hline
\end{tabular}

${ }^{(1)} \mathrm{DP}$ : desvio padrão. ${ }^{(2)} \mathrm{CV}$ : coeficiente de variação.

observou-se variação nos resultados médios, entre os tamanhos dos frutos P, MP, MG e G $(2,03 \mathrm{~mm}$, 2,15 mm, 2,24 $\mathrm{mm}$ e 2,17 $\mathrm{mm}$, respectivamente). Para a massa das sementes, os frutos P, MP, MG e G apresentaram valores médios de $0,256 \mathrm{~g}, 0,0325 \mathrm{~g}$, $0,0467 \mathrm{~g}$ e $0,0504 \mathrm{~g}$, respectivamente.

$\mathrm{O}$ número de sementes por fruto variou em função do tamanho dos frutos P, MP, MG e G, apresentando resultados médios para sementes íntegras de 2,$15 ; 3,05 ; 3,30$; e 4,3 sementes por fruto, respectivamente (Tabela 3). Com relação ao número de sementes vazias, observou-se que os valores médios para os frutos $\mathrm{P}, \mathrm{MP}, \mathrm{MG}$ e G foram de 2,$55 ; 2,15$; 2,25 ; e 2,25 sementes por fruto, respectivamente. Os valores médios do número total de sementes, nos frutos P, MP, MG e G, foram de 4,7; 5,2; 5,55; e 6,75 sementes por fruto, respectivamente.

De acordo com os resultados ilustrados nas Tabelas 2 e 3, os tamanhos dos frutos influenciaram nos resultados de comprimento, largura, massa, número de sementes íntegra e total, aumentando, significativamente, de acordo com o diâmetro dos frutos. Estes resultados sugerem que o ambiente de ocorrência de $C$. adamantium proporciona variações no número de sementes, em função dos frutos coletados em diferentes matrizes. Contudo, as classes de tamanho dos frutos não influenciaram nos resultados de espessura e número de sementes vazias. Resultados semelhantes foram observados por Ferreira \& Torres (2000), que não verificaram influência do tamanho dos frutos na espessura de sementes de Acacia senegal (L.) de Willd.

As curvas de absorção de água das sementes de $C$. adamantium provenientes de frutos $\mathrm{P}, \mathrm{MP}, \mathrm{MG}$ e $G$ não apresentaram o padrão trifásico do processo germinativo (Figura 2). Houve aumento elevado na absorção de água durante a primeira hora de embebição, a qual apresentou-se lenta e constante, nas horas seguintes, até a emissão da raiz primária, impedindo a determinação pontual das fases de germinação das sementes. Assim, o comportamento de embebição observado não pode ser caracterizado como o padrão trifásico proposto por Bewley \& Black (1994), que apresenta uma fase inicial de absorção rápida de água, seguida por uma fase estacionária, finalizando-se com um novo aumento, o qual coincide com a protrusão da raiz primária.

Para as sementes provenientes de frutos $\mathrm{P}$ e MP, observou-se protrusão da raiz primária a partir de 84 horas ( $3^{\circ}$ dia) e, para os frutos $M G$ e $G$, a partir de 108 horas ( $4^{\circ}$ dia) do início da embebição. As sementes provenientes de frutos P e MP, por 
Tabela 3. Número de sementes por fruto de gabiroba (Campomanesia adamantium), em função do tamanho dos frutos (Dourados, MS, 2011).

\begin{tabular}{|c|c|c|c|c|c|}
\hline \multirow{2}{*}{ Característica da semente } & \multicolumn{3}{|c|}{ Valor } & \multirow{2}{*}{$\mathrm{DP}^{(1)}$} & \multirow{2}{*}{$\mathrm{CV}(\%)^{(2}$} \\
\hline & Mínimo & Médio & Máximo & & \\
\hline \multicolumn{6}{|c|}{ Fruto pequeno $(P)$} \\
\hline Semente íntegra & 1 & 2,15 & 5 & 1,387 & 64,51 \\
\hline Semente vazia & 1 & 2,55 & 4 & 0,945 & 37,04 \\
\hline Total & 3 & 4,70 & 6 & 1,129 & 24,01 \\
\hline \multicolumn{6}{|c|}{ Fruto médio pequeno (MP) } \\
\hline Semente íntegra & 1 & 3,05 & 6 & 1,504 & 49,30 \\
\hline Semente vazia & 0 & 2,15 & 5 & 1,226 & 57,01 \\
\hline Total & 3 & 5,20 & 7 & 1,240 & 23,84 \\
\hline \multicolumn{6}{|c|}{ Fruto médio grande $(M G)$} \\
\hline Semente íntegra & 2 & 3,30 & 6 & 1,302 & 39,45 \\
\hline Semente vazia & 0 & 2,25 & 5 & 1,552 & 68,97 \\
\hline Total & 4 & 5,55 & 7 & 0,759 & 13,68 \\
\hline \multicolumn{6}{|c|}{ Fruto grande $(G)$} \\
\hline Semente íntegra & 1 & 4,30 & 7 & 1,750 & 40,70 \\
\hline Semente vazia & 0 & 2,45 & 6 & 1,877 & 76,62 \\
\hline Total & 5 & 6,75 & 8 & 0,967 & 14,42 \\
\hline
\end{tabular}

(1) DP: desvio padrão. ${ }^{(2)} \mathrm{CV}$ : coeficiente de variação.

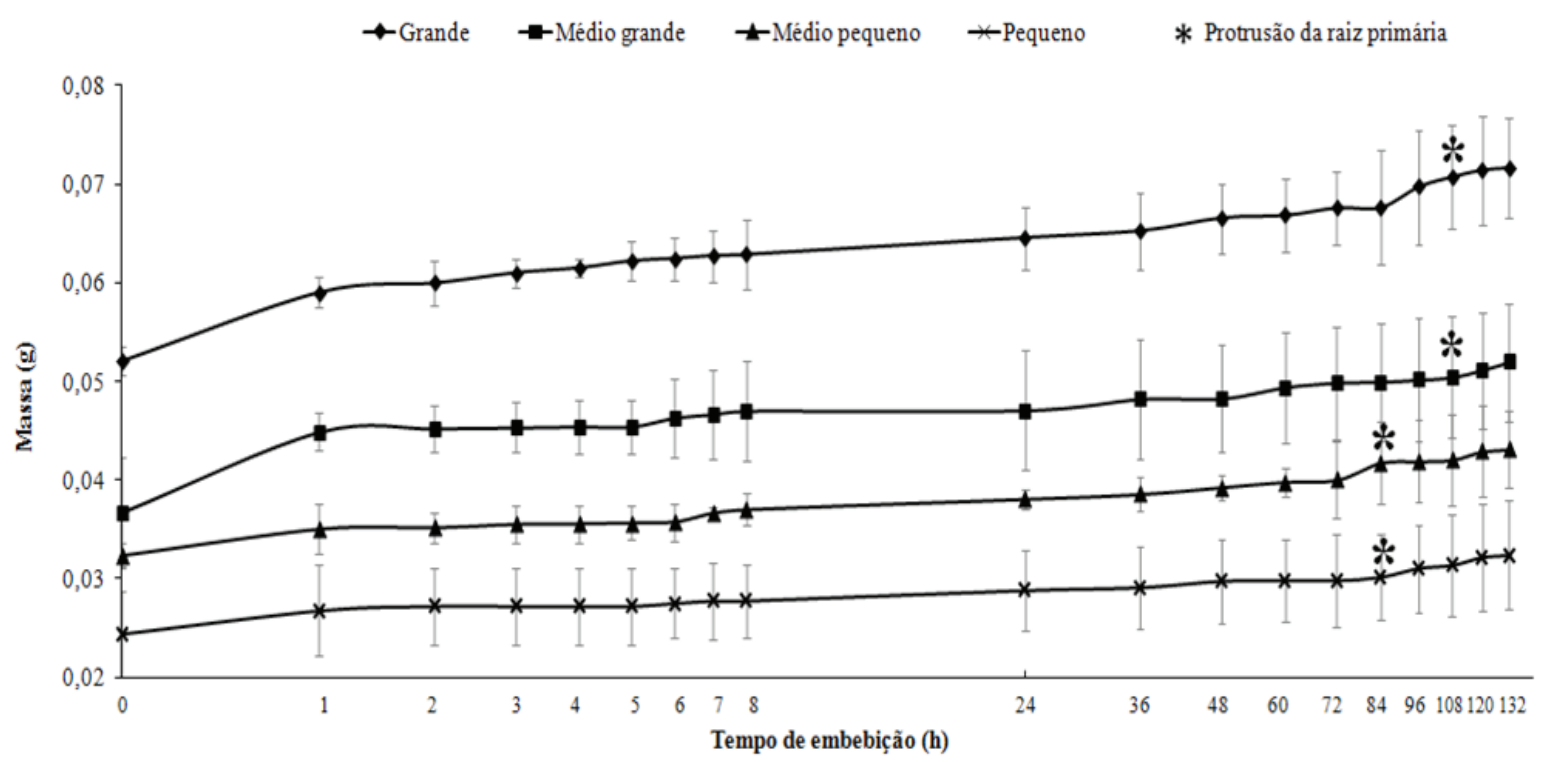

Figura 2. Curva de absorção de água das sementes de Campomanesia adamantium provenientes de frutos com diferentes tamanhos (Dourados, MS, 2011).

apresentarem as menores dimensões e massas de sementes, deram origem a uma rápida protrusão da raiz primária, em relação aos demais tamanhos de frutos. Estes resultados são explicados por Harper et al. (1970), ao relatarem que sementes pequenas têm maior facilidade em obter água para germinação do que sementes grandes, devido à maior razão superfície/volume.
Na Tabela 4, encontram-se os resultados para o potencial fisiológico das sementes, em função das classes dos frutos. O grau de umidade das sementes foi maior em sementes provenientes dos frutos MG e $\mathrm{G}(33,5 \%$ e $33,9 \%$, respectivamente $)$ e menor em frutos P $(28,5 \%)$. Resultados semelhantes foram observados por Melchior et al. (2006), os quais relataram que sementes provenientes de frutos com 
Tabela 4. Grau de umidade (GU), germinação (G), índice de velocidade de germinação (IVG), comprimento da parte aérea (CPA), comprimento da raiz (CR), comprimento total (CT), massa fresca total (MFT) e massa seca total (MST) de Campomanesia adamantium, em função das classes de frutos (Dourados, MS, 2011).

\begin{tabular}{|c|c|c|c|c|c|c|c|c|}
\hline \multirow{2}{*}{ Classe de fruto $^{(2)}$} & GU & $\mathrm{G}$ & \multirow{2}{*}{ IVG } & $\mathrm{CPA}$ & $\mathrm{CR}$ & CT & MFT & MST \\
\hline & \multicolumn{2}{|c|}{$\%$} & & \multicolumn{3}{|c|}{ cm plântula ${ }^{-1}$} & \multicolumn{2}{|c|}{ g plântula $^{-1}$} \\
\hline $\mathrm{P}$ & $29,4 b^{(1)}$ & 87,0 a & $2,889 \mathrm{a}$ & $4,02 \mathrm{a}$ & $5,27 \mathrm{a}$ & $9,31 \mathrm{a}$ & $0,0815 \mathrm{~b}$ & $0,1550 \mathrm{c}$ \\
\hline MP & $28,5 \mathrm{c}$ & 86,0 a & $2,267 \mathrm{ab}$ & $4,81 \mathrm{a}$ & $4,51 \mathrm{ab}$ & $9,29 \mathrm{a}$ & $0,9863 \mathrm{a}$ & $0,1860 \mathrm{bc}$ \\
\hline MG & $33,5 \mathrm{a}$ & $79,0 \mathrm{ab}$ & $2,132 \mathrm{ab}$ & $4,35 \mathrm{a}$ & $4,85 \mathrm{a}$ & 9,19 a & $0,1076 \mathrm{a}$ & $0,0235 \mathrm{ab}$ \\
\hline $\mathrm{G}$ & $33,7 \mathrm{a}$ & $72,0 \mathrm{~b}$ & $1,712 \mathrm{~b}$ & $4,01 \mathrm{a}$ & $3,68 \mathrm{~b}$ & $7,70 \mathrm{a}$ & $0,1115 \mathrm{a}$ & $0,0261 \mathrm{a}$ \\
\hline
\end{tabular}

${ }^{(1)}$ Médias seguidas da mesma letra minúscula, na coluna, não diferem, significativamente, entre si, pelo Teste Tukey, a 5\%. ${ }^{(2)} \mathrm{P}:$ pequeno; MP: médio pequeno; MG: médio grande; G: grande.

diâmetro médio de $2,21 \mathrm{~cm}$ apresentaram $30 \%$ de teor de água. Entretanto, Oliveira et al. (2011) encontraram teores de água de $54,98 \pm 4,20 \%$, para sementes de $C$. adamantium, e Dresch et al. (2012) verificaram $57 \%$ de teor de água, em sementes recém-processadas de C. adamantium. As diferenças encontradas podem estar associadas à pré-secagem superficial de 30 minutos, realizada anteriormente aos testes e que, possivelmente, ocasionou a redução no teor de água das sementes.

As percentagens de germinação foram maiores em sementes provenientes dos frutos $\mathrm{P}(87 \%)$, MP (86\%) e MG (79\%), que não diferiram significa- tivamente entre si, e os menores resultados foram observados para sementes de frutos G (72\%) (Tabela 4). Resultados semelhantes foram verificados para a velocidade de germinação, que foi maior em sementes provenientes de frutos $\mathrm{P}(2,889), \mathrm{MP}(2,2673) \mathrm{e}$ MG $(2,1326)$, que não diferiram significativamente entre si, sendo observado que sementes de frutos $G$ apresentaram o menor IVG $(1,712)$. As sementes provenientes de frutos $\mathrm{P}$ apresentaram os maiores resultados de germinação e velocidade de germinação, sendo verificada alta correlação da germinação com as dimensões das sementes provenientes de frutos P (Tabela 5). De acordo com Krzyzanowski et al.

Tabela 5. Coeficiente de correlação simples entre os resultados de germinação (G), índice de velocidade de germinação (IVG), comprimento da parte aérea (CPA), comprimento da raiz (CR), comprimento total (CT), massa fresca total (MFT) e massa seca total (MST) e das dimensões e massas das sementes, em função dos tamanhos dos frutos de gabiroba (Campomanesia adamantium) (Dourados, MS, 2011).

\begin{tabular}{|c|c|c|c|c|c|c|c|}
\hline Variáveis & $\mathrm{G}$ & IVG & $\mathrm{CPA}$ & $\mathrm{CR}$ & CT & MFT & MST \\
\hline \multicolumn{8}{|c|}{ Comprimento $(\mathrm{mm})$} \\
\hline Pequeno & 0,53 & $-0,31$ & $-0,43$ & $-0,45$ & $-0,45$ & $-0,39$ & $-0,09$ \\
\hline Médio pequeno & $-0,79$ & 0,47 & 0,04 & $-0,21$ & $-0,18$ & $-0,18$ & $-0,55$ \\
\hline Médio grande & 0,13 & $-0,78$ & 0,03 & 0,15 & 0,11 & 0,84 & 0,61 \\
\hline Grande & $-0,93$ & $-0,93$ & 0,93 & $-0,93$ & $-0,93$ & 0,93 & 0,93 \\
\hline \multicolumn{8}{|c|}{$\operatorname{Largura}(\mathrm{mm})$} \\
\hline Pequeno & 0,74 & 0,45 & 0,84 & 0,87 & 0,88 & 0,82 & 0,96 \\
\hline Médio pequeno & 0,61 & $-0,66$ & 0,11 & 0,48 & 0,45 & 0,13 & 0,41 \\
\hline Médio grande & 0,14 & $-0,03$ & $-0,82$ & $-0,41$ & $-0,60$ & $-0,70$ & $-0,23$ \\
\hline Grande & $-0,91$ & $-0,91$ & 0,91 & $-0,91$ & $-0,91$ & 0,91 & 0,91 \\
\hline \multicolumn{8}{|c|}{ Espessura $(\mathrm{mm})$} \\
\hline Pequeno & 0,60 & 0,39 & 0,85 & 0,94 & 0,93 & 0,81 & 0,99 \\
\hline Médio pequeno & 0,32 & $-0,27$ & $-0,90$ & $-0,23$ & $-0,41$ & 0,92 & 0,99 \\
\hline Médio grande & 0,64 & $-0,15$ & 0,57 & 0,78 & 0,74 & 0,96 & $-0,05$ \\
\hline Grande & $-0,87$ & $-0,87$ & 0,87 & $-0,87$ & $-0,87$ & 0,87 & 0,87 \\
\hline \multicolumn{8}{|c|}{ Massa (g) } \\
\hline Pequeno & $-0,71$ & 0,16 & 0,19 & 0,22 & 0,21 & 0,16 & $-0,15$ \\
\hline Médio pequeno & 0,13 & $-0,50$ & 0,81 & 0,75 & 0,85 & $-0,56$ & $-0,45$ \\
\hline Médio grande & $-0,46$ & 0,70 & 0,30 & $-0,15$ & 0,01 & $-0,59$ & $-0,32$ \\
\hline Grande & $-0,93$ & $-0,93$ & 0,93 & $-0,93$ & $-0,93$ & 0,93 & 0,93 \\
\hline
\end{tabular}


(1999), as sementes menores, por necessitarem de menor quantidade de água, são as primeiras a germinar.

De maneira semelhante, sementes de Mimosa caesalpiniifolia Benth, de tamanho pequeno, apresentaram os maiores resultados de velocidade de germinação (Alves et al. 2005). Entretanto, Klein et al. (2007) observaram que as sementes de tamanho médio e grande foram as que apresentaram maiores médias de emergência de plântulas de pitanga (Eugenia uniflora L.). Por outro lado, Paz et al. (1999) não encontraram efeito significativo entre o tamanho da semente e a percentagem e velocidade de emergência de plântulas de sete espécies de Psychotria (Rubiaceae). Desta forma, a influência da massa de sementes na germinação e no vigor de plântulas parece ser específica, variando entre espécies e entre regiões distintas (Pereira et al. 2011).

Os comprimentos da parte aérea e total das plântulas não variaram significativamente entre os tamanhos dos frutos, sugerindo que a variação entre as classes não interfere no crescimento total da plântula (Tabela 4). Para o comprimento das raízes, os maiores resultados foram observados em sementes provenientes dos frutos $\mathrm{P}\left(5,27 \mathrm{~cm}\right.$ plântula $\left.\mathrm{a}^{-1}\right)$, MP (4,51 cm plântula $\left.{ }^{-1}\right)$ e MG $\left(4,85 \mathrm{~cm}\right.$ plântula $\left.\mathrm{a}^{-1}\right)$, que não variaram significativamente entre si, evidenciando as sementes de frutos $\mathrm{G}$ como as de menor comprimento de raiz.

Para a massa fresca total das plântulas, as sementes provenientes dos frutos G, MG e MP apresentaram os maiores resultados e elevada correlação com a espessura, largura (G), comprimento (MG e $\mathrm{G})$ e massa das sementes (G) (Tabelas 4 e 5). Estes resultados estão de acordo com os obtidos por Oliveira et al. (2011), ao observarem que os frutos de maior volume, com maior acúmulo de massa fresca e maior amplitude biométrica de $C$. pubescens e C. adamantium, apresentaram potencial para seleção de materiais promissores, para fins de melhoramento.

Com relação à massa seca total, as sementes provenientes de frutos $\mathrm{G}\left(0,0261 \mathrm{~g}_{\text {plântula }}{ }^{-1}\right)$ e MG $\left(0,0235 \mathrm{~g}\right.$ plântula $\left.^{-1}\right)$ apresentaram os maiores resultados, em relação às demais classes de tamanhos (Tabela 4). Ressalta-se que houve uma relação direta entre as sementes provenientes de frutos da classe $\mathrm{G}$, consequentemente com as sementes de maiores massa e que apresentaram os maiores acúmulos de biomassa, evidenciando a maior capacidade de transferência de reservas para a plântula. Observou-se, ao mesmo tempo, correlação positiva entre as dimensões, massa das sementes e massa seca total das plântulas provenientes de frutos $\mathrm{G}$, indicando que esta característica pode ser eficiente para detectar diferenças de vigor entre as classes de tamanho de frutos (Tabela 5).

De acordo com Carvalho \& Nakagawa (2012), em uma mesma espécie, as sementes de maior peso, por serem mais bem nutridas durante o seu desenvolvimento, possuem embriões bem formados e com maior quantidade de reservas, sendo, por conseguinte, mais vigorosas e originando plântulas mais desenvolvidas.

Para C. adamantium, a extração de sementes a partir das classes de frutos $\mathrm{P}, \mathrm{MP}$ e MG proporcionou sementes com maior percentagem e velocidade de germinação, além de maior comprimento de raiz. Entretanto, sementes oriundas de frutos grandes podem representar a obtenção de plântulas com elevado acúmulo de biomassa, que, possivelmente, originarão mudas mais vigorosas e com maior capacidade de sobrevivência, em condições inóspitas.

O coeficiente de correlação para o comprimento das sementes foi positivo entre sementes provenientes dos frutos $\mathrm{P}$, para germinação $(0,53)$; frutos MP, para o IVG $(0,47)$; e frutos MG, para a massa fresca total $(0,84)$ e massa seca total de plântulas $(0,61)$ (Tabela 5).

Com relação à largura, as sementes provenientes dos frutos $\mathrm{P}$ apresentaram correlação positiva, para todos os parâmetros de vigor (Tabela 5). Para os frutos MP, as correlações foram positivas para a germinação $(0,61)$, comprimento de raiz $(0,48)$ e comprimento total de plântulas $(0,45)$. A espessura de sementes correlacionou-se positivamente, para todas as características de vigor de sementes provenientes de frutos P. Os frutos MP apresentaram correlação positiva entre a espessura e a germinação $(0,32)$, a massa fresca total $(0,92)$ e massa seca total de plântulas $(0,99)$, indicando a influência do tamanho dos frutos e da espessura da semente sobre estas características.

As sementes provenientes de frutos MG apresentaram correlação positiva entre a espessura e as características de vigor, exceto para o IVG $(-0,50)$ e a massa seca total $(-0,05)$, que apresentaram correlação negativa (Tabela 5).

Com relação à massa, as sementes provenientes de frutos P correlacionaram-se positivamente com todas as características, exceto para a germinação $(-0,71)$ e a massa seca total $(-0,15)$. Verificou-se cor- 
relação positiva elevada entre as massas de sementes provenientes de frutos MP, para o comprimento de plântulas (parte aérea: 0,81 ; raiz: 0,75 ; total: 0,85 ), sendo que, para os frutos $\mathrm{MG}$, observou-se 0,70 , para o IVG, e 0,30 , para o comprimento da parte aérea.

As sementes provenientes de frutos $G$ apresentaram correlação positiva entre as dimensões e massas de sementes, para o comprimento da parte aérea, massa fresca e seca total de plântulas, demonstrando que o acúmulo de biomassa pelas plântulas é proporcional às dimensões da semente (Tabela 5). Segundo Surles et al. (1993), sementes maiores produzem plântulas mais vigorosas, presumivelmente porque possuem mais material de reserva, maior nível de hormônio e maior embrião.

\section{CONCLUSÕES}

1. Os frutos de gabiroba apresentaram diferentes tamanhos, os quais relacionaram-se diretamente com as dimensões e massas das sementes, além de influenciarem na germinação e vigor das sementes.

2. Frutos classificados como pequeno, médio pequeno e médio grande apresentaram sementes com maior percentagem e velocidade de germinação, enquanto sementes oriundas de frutos grandes produziram plântulas com maior acúmulo de biomassa.

\section{REFERÊNCIAS}

ALVES, E. U. et al. Influência do tamanho e da procedência de sementes de Mimosa caesalpiniifolia Benth. sobre a germinação e vigor. Revista Árvore, Viçosa, v. 29, n. 6, p. 877-885, 2005.

BEWLEY, J. D.; BLACK, M. Seeds: physiology of development and germination. 2. ed. New York: Plenum Press, 1994.

BEZERRA, A. M. E.; MOMENTÉ, V. G.; MEDEIROS FILHO, S. Germinação de sementes e desenvolvimento de plântulas de moringa (Moringa oleifera Lam.) em função do peso da semente e do tipo de substrato. Horticultura Brasileira, Brasília, DF, v. 22, n. 2, p. 295-299, 2004.

BORTOLOTTO, R. P. et al. Comportamento de hidratação e qualidade fisiológica das sementes de arroz. Bragantia, Campinas, v. 67, n. 4, p. 991-996, 2008.

BRASIL. Ministério da Agricultura, Pecuária e Abastecimento. Secretaria de Defesa Agropecuária. Regras para análises de sementes. Brasília, DF: MAPA/ ACS, 2009.
CARVALHO, N. M.; NAKAGAWA, J. Sementes: ciência, tecnologia e produção. 4. ed. Jaboticabal: Funep, 2000.

CARVALHO, N. M.; NAKAGAWA, J. Sementes: ciência, tecnologia e produção. 5. ed. Jaboticabal: Funep, 2012.

COSTA, R. S. et al. Aspectos morfológicos e influência de tamanho da semente na germinação de jambeiro vermelho. Revista Brasileira de Fruticultura, Jaboticabal, v. 28, n. 1, p. 117-120, 2006.

CRUZ, E. D.; CARVALHO, J. E. U. Biometria de frutos e germinação de sementes de Couratari stellata A. C. Smith (Lecythidaceae). Acta Amazonica, Manaus, v. 33, n. 3, p. 381-388, 2003.

DONADIO, N. M. M.; DEMATTÊ, M. E. S. P. Morfologia de frutos, sementes e plântulas de canafístula (Peltophorum dubium (Spreng) Taub.) e jacarandá-da-Bahia (Dalbergia nigra (Vell.) Fr. All. ex Benth.) - Fabaceae. Revista Brasileira de Sementes, Brasília, DF, v. 22, n. 1, p. 64-73, 2000.

DRESCH, D. M. et al. Germinação de sementes de Campomanesia adamantium (Camb.) O. Berg em diferentes temperaturas e umidades do subtrato. Scientia Forestalis, Piracicaba, v. 40, n. 94, p. 223-229, 2012.

FERREIRA, D. F. Sisvar: um programa para análises e ensino de estatística. Revista Symposium, Campinas, v. 6, n. 1, p. $36-41,2008$.

FERREIRA, M. G. R.; TORRES, S. B. Influência do tamanho das sementes na germinação e no vigor de plântulas de Acacia senegal (L.) de Willd. Revista Brasileira de Sementes, Brasília, DF, v. 22, n. 1, p. 271275, 2000.

HAIG, D.; WESTOBY, M. Seed size, pollination casts and angiosperm success. Evolutionary Ecology, Tucson, v. 5, n. 2, p. 231-247, 1991.

HARPER, J. L.; LOVEL, P. H.; MOORE, K. G. The shapes and sizes of seeds. Annual Review of Ecology and Systematics, Palo Alto, v. 1, n. 1, p. 327-356, 1970.

KLEIN, J. et al. Efeito do tamanho da semente na emergência e desenvolvimento inicial de mudas de pitangueira (Eugenia uniflora L.). Revista Brasileira de Biociências, Porto Alegre, v. 5, n. 2, p. 861-863, 2007.

KRZYZANOWSKI, F. C.; VIEIRA, R. D.; FRANÇA NETO, J. B. Vigor de sementes: conceitos e testes. Londrina: Abrates, 1999.

LORENZI, H. et al. Frutas brasileiras e exóticas cultivadas (de consumo in natura). São Paulo: Instituto Plantarum, 2006.

MAGUIRE, J. D. Speed of germination-aid in selection and evaluation for seedling emergence and vigor. Crop Science, Madison, v. 2, n. 1, p. 176-177, 1962. 
MELCHIOR, S. J. et al. Colheita e armazenamento de sementes de gabiroba (Campomanesia adamantium Camb. - Myrtaceae) e implicações na germinação. Revista Brasileira de Sementes, Brasília, DF, v. 28, n. 3, p. 141150, 2006.

NOGUEIRA, F. C. B.; MEDEIROS FILHO, S.; GALLAO, M. Caracterização da germinação e morfologia de frutos, sementes e plântulas de Dalbergia cearensis Ducke (pauvioleta) - Fabaceae. Acta Botanica Brasilica, Feira de Santana, v. 24, n. 4, p. 978-985, 2010.

OLIVEIRA, M. C.; SANTANA, D. G.; SANTOS, C. M. Biometria de frutos e sementes e emergência de plântulas de duas espécies frutíferas do gênero Campomanesia. Revista Brasileira de Fruticultura, Jaboticabal, v. 33, n. 2 , p. 446-455, 2011.

PAOLI, A. A. S.; BIANCONI, A. Caracterização morfológica de frutos, sementes e plântulas de Pseudima frutescens (Aubl.) Radlk. (Sapindaceae). Revista Brasileira de Sementes, Londrina, v. 30, n. 2, p. 146-155, 2008.

PAZ, H.; MAZER, S. J.; MARTINEZ-RAMOS, M. Seed mass, seedling emergence, and environmental factors in seven rainforest Psychotria (Rubiaceae). Ecology, Ithaca, v. 80, n. 5 , p. 1594-1606, 1999.
PEREIRA, S. R. et al. Tamanho de frutos e de sementes e sua influência na germinação de jatobá-do-cerrado (Hymenaea stigonocarpa var. stigonocarpa Mart. ex Hayne, Leguminosae - Caesalpinoideae). Revista Brasileira de Sementes, Londrina, v. 33, n. 1, p. 141-148, 2011.

RAMOS, M. B. P.; FERRAZ, I. D. K. Estudos morfológicos de frutos, sementes e plântulas de Enterolobium schomburgkii Benth. (Leguminosae-Mimosoideae). Revista Brasileira de Botânica, São Paulo, v. 31, n. 2, p. 227-235, 2008.

SURLES, S. E.; WHITE, T. L.; HODGE, G. P. Relationships among seed weight components, seedling growth traits, and predicted field breeding values in slash pine. Canadian Journal of Forest Research, Ottawa, v. 23, n. 8, p. 15501556, 1993.

TORRES, S. B. Influência do tamanho das sementes de Acacia gomifera no desenvolvimento das mudas. Agropecuária Catarinense, Florianópolis, v. 7, n. 2, p. 5, 1994.

VALLILO, M. I. et al. Composição química dos frutos de Campomanesia adamantium (Cambessedes) O. Berg. Ciência e Tecnologia de Alimentos, Campinas, v. 26, n. 4 , p. 805-810, 2006. 